\title{
Some Studies on Strangles in Cairo and Giza Governorates
}

\author{
O. M. Mohamed"Amal A. El-Molla**, W. R. El-Ashmawy ${ }^{* *}$ and H. A. Hatem ${ }^{* * * *}$ \\ ${ }^{*}$ Giza Zoo, General Organization Veterinary Services, ${ }^{* *}$ Department of Internal Medicine \\ and Infectious Diseases, Faculty of Veterinary Medicine, Cairo University and ${ }^{* * *}$ Animal \\ Production Branch, National Service Projects Organization, Cairo, Egypt.
}

\begin{abstract}
$\mathbf{T}$ HE PRESENT work was designed to study the relation between the rate of strangles infectionin equine and seasonal incidence in Cairo and Giza governorates, beside the isolation and identification of Streptococcus equi. Seventyeight horses of different ages have been studied for S.equiinfection alongthe period lasted between January 2014 and December 2015. The most frequent clinical symptoms was the nasal discharge $(100 \%)$, then signs like abscess formation and fever have been presented by $71.8 \%$ and $33.3 \%$ respectively. Most of clinical cases have been detected in age of six to twelve months $(71.15 \%)$. Most of stranglespositive cases have recorded in winter season $(60.03 \%)$ followed by spring $(20 \%)$ and summer (18\%). According to the biochemical results $75 \%$ of clinical cases caused by $S$. equi followed by $S$. zooepidemicus.S. equiinfection has been confirmed by the PCR technology through detection of Sod A gene.
\end{abstract}

Keywords: Strangles, Streptococcusequi, Streptococcus zooepdemicus, Seasonal incidence, Lymph node, Clinical signs and PCR.

\section{Introduction}

Strangles is one of the most important horse diseases in both of the developing and developed countries where it accounts for up to $30 \%$ of reported infectious disease episodes [1]. High morbidity rate could be apparent especially in foals (48\%) with low mortality rate in $1-2 \%$ in the properly cared cases. The mortality rate can reach $9 \%$ in the complicated cases due to pneumonia [2].

Strangles can be observed extremely at the end of the rainy season and looks as acute attacks of outbreaks of high morbidity and low deaths rates [3].

The clinical picture of strangles become apparent following an incubation period varies from 3 to 8 days [4]. The clinical course usually lasts 3 to 4 weeks, marked fever (39.5$41^{\circ} \mathrm{C}$ ) develops during the acute phase and may subside until the abscess formation in the lymph nodes; this is the time when a second wave of fever may develop. Anorexia, depression, and bilateral, serous to mucous nasal discharge could be appeared within 24 hours of fever. The nasal discharge becomes mucopurulent as the disease progresses, and a moist cough may develop in some cases [5]. Enlargement, sever pain and abscess formation may involve the submandibular lymph nodes and the retropharyngeal which can lead to dysphagia [6], the affected lymph nodes typically rupture within 7 to 10 days after the onset of clinical signs.
The convalescence period may be varied from 1 to 2 weeks in the uncomplicated cases $[7,8]$.

The diagnosis of strangles is based on clinical symptoms and laboratory findings by cultivation on culture and PCR technology [9].

Isolates of streptococcus species that can be recovered from the pus samples include $\mathrm{S}$. equi subspecies equi $(54 \%)$, S. equi subspecies zooepidemicus (11\%), S. dysgalactia subspecies equisimilis (11\%) and mixed isolates of $\mathrm{S}$. equisimilis and S. equi (23\%) [10]. Due to the similarity in the DNA of $\mathrm{S}$. equi and $\mathrm{S}$. zooepidemicus (98\%), the use of PCR technology to identify S. equi is extremely helpful, as both of them are pathogenic for horses [11].

\section{Material and Methods}

The present study was conducted on randomly selected 78 horses of different sexes, their age ranged between 6 months and 5 years old. The clinical examination showed the typical symptoms of strangles including (fever, nasal discharge, cough and swelling of submandibular and retropharyngeal lymph nodes). Investigation of the affected animals was performed in the Nazlet El Semman area, Alzahraa Stud and Brook Hospital during period from January 2014 to December 2015. 
Samples: swabs or material obtained from drained abscesses can be cultured for bacterial growth and/ or for PCR testing. Two swabs were introduced into the nares at the same time and kept in contact with the mucosa for a minimum of 20 seconds to insure good contact. One swab can be used for bacterial culture and the other for PCR.

Smears from suspected colonies were stained by Gram`s stain and examined for Gram positive minute cocci in chain like arrangement.

\section{Biochemical Identification}

For the catalase test, the suspected colonies were subcultured on brain heart agar slope and incubated for overnight at $37^{\circ} \mathrm{C}$ followed by adding drop of $\mathrm{H} 2 \mathrm{O} 2$ (3\%) was added. Positive result could be detected as appearance of multiple bubbles due to the rapid evolution of oxygen within 5 to 10 seconds [12].

For the Oxidase test, the suspected colonies were subcultured on brain heart agar slope medium and incubated overnight at $37^{\circ} \mathrm{C}$. The suspected positive colonies were captured sterile loop then smeared with fresh oxidase strip in Petri-dish. The positive results could be indicated by deep purple color within 5 to 60 seconds [12].

For sugar fermentation test, bacterial colonies were cultivated on brain heart infusion agar media for magnification ( $24 \mathrm{hrs}$ at $37 \mathrm{c}$ ). The cultivated colonies were tested for sugar fermentation by using of ready prepared trehalose, sorbitol, maltose and lactose separately after incubation at $37^{\circ} \mathrm{C}$ for 24 hours [13].

\section{For the Molecular detection by the PCR assay}

The collected clinical samples were submitted for DNA extraction step using a commercially available genomic DNA extraction kit (QIAamp® DNA Mini Kit, Qiagen). DNA extraction procedures were performed according the manufacturer guidelines. DNA extracts were stored at $-20^{\circ} \mathrm{C}$ till used for the Polymerase Chain Reaction (PCR) assay.

Molecular detection was attempted for rapid detection of $S$. equi species. Therefore, two distinct PCR assay largely based on previously published data were used. The first PCR assay was attempted to detect a DNA fragment encoding Sod A gene which is specific for S.equis ubsppequi, the second PCR assay was used to detect SeM gene which is specific for S.equi sub sppZooepidimicus. For the S.equi sub sppequi, PCR assay used Sod A Forward primer (5' - CAG CAT TCC TGC TGA CAT TCG TCA GG -3') and Sod A Reverse primer (5'-CTG ACC AGC ATT ATT CAC AAC CAG CC -3') to obtain a PCR product of $235 \mathrm{bp}$. For S.equi sub sppZooepidimicus PCR assay, SeM Forward primer (5'-TGCATAAAGAAGTTCCTGTC-3') and SeM Reverse primer (5'-GATTCGGTAAGAGCTTGACG-3') were used to obtain a PCR product of $679 \mathrm{bp}$. For the PCR reaction, primers concentration were adjusted to obtain 20 pmol of each primer in $1 \mu \mathrm{l}$, then adding $1 \mu \mathrm{l}$ of each primer, $12.5 \mu \mathrm{l}$ of master mix solution (Qiagen), $5 \mu \mathrm{l}$ of extracted DNA and $5.5 \mu \mathrm{l}$ nuclease free water to get a final volume of $25 \mu 1$.

The thermal cycling conditions for both PCR assays were $5 \mathrm{~min}$ at $94^{\circ} \mathrm{C}$ as initial denaturation followed by 35 cycles, each consisting of denaturation step at $94^{\circ} \mathrm{C} / 30 \mathrm{~s}$ (the annealing step for S.equi sub sppequi was adjusted at $70^{\circ} \mathrm{C} / 10 \mathrm{~s}$ and for $\mathrm{S}$. equi sub sppzooepidimicus at $56^{\circ} \mathrm{C} / 10 \mathrm{~s}$ ) then extension at $72^{\circ} \mathrm{C}$ for $2 \mathrm{~min}$ which finished with a final extension step at $72^{\circ} \mathrm{C}$ for $7 \mathrm{~min}$. Amplification was performed using of the AppliedBiosystemVeriti ${ }^{\circledR}$ thermal cycle (USA). Following to the amplification steps, 10 $\mu l$ of each PCR product was electrophoresed on $1-2 \%$ agarose gel and visualized using an UV transilluminator [14]

\section{$\underline{\text { Results }}$}

\section{Clinical examination}

The typical clinical signs for strangles were obviously detected during the clinical investigation, most of the affected animals showed fever $\left(39.4-41.3^{\circ} \mathrm{C}\right)$, cough and unilateral and/or bilateral nasal discharge which converted from serous into purulent nature, as well the abscessation of upper respiratory lymphnodes mainly the submandibular lymph nodes. The classical lymphadenitis symptoms were recorded in 56 animals out of 78 clinically affected cases. The recorded clinical signs were represented as shown in Table 1. 
TABLE 1. Number and percent of different clinical signs in positive cases.

\begin{tabular}{lcccccc}
\hline Symptoms & Cough & $\begin{array}{c}\text { Nasal } \\
\text { discharge }\end{array}$ & Fever & $\begin{array}{c}\text { Complication } \\
\text { (abscess formation in } \\
\text { different internal organs) }\end{array}$ & $\begin{array}{c}\text { Lymph } \\
\text { node } \\
\text { abscess }\end{array}$ & $\begin{array}{c}\text { Total } \\
\text { positive } \\
\text { cases }\end{array}$ \\
\hline $\begin{array}{l}\text { Number of } \\
\text { cases }\end{array}$ & 19 & 56 & 39 & 1 & 48 & 56 \\
Percent & $33.92 \%$ & $100 \%$ & $69.9 \%$ & $1.79 \%$ & $58.71 \%$ & $100 \%$ \\
\hline
\end{tabular}

Post mortem changes

Post mort examination showed variable pathological changes especially within the upper respiratory tract and it's related lymph nodes in regions of head and neck. Sever congestive changes were seen on the mucosal surfaces of nasal passage, conchae and larynx. In addition to the frothy and purulent exudates were detected filling the sinuses, creamy yellowish exudates were also detected filling the guttural pouch. Besides the pulmonary congestive changes, multiple abscesses were revealed in both lungs. Hemorrhagic petichaes with ecchymotic patches covering the surfaces of coronary fats, myocardium and renal capsules.

Results of Bacteriological and Biochemical identification

According to the bacteriological examination (appeared as long chain under 100x), the isolates were Gram-positive, $\beta$-hemolytic on edward's media. The size of colonies were small, convex, glistening, moist, mucoid and transparent colonies.

All isolated colonies were catalase and oxidase negative, in addition to variation in ability to ferment trehalose, sorbitol and lactose.

Biochemical identification revealed $75 \%$ of cases infected by S.equi and $25 \%$ of cases infected by $S$. zooepidemicus.

PCR and Epidemiological results

Existence of Streptococcus spp DNA was confirmed by PCR assays in 56 out of 78 animals. Correlation between the PCR results with the seasonal incidence and the age was demonstrated in Table 3.

Antimicrobial sensitivity test of isolates All fifty six examined isolates were resistant to all used antibiotic discs except penicillin $\mathrm{G}$ andofloxacin.

TABLE 2. Differentiation of equine group C streptococci by suger fermentation [12].

\begin{tabular}{lcccc}
\hline & Trehalose & Sorbitol & Lactose & Maltose \\
\hline S. equi & - & - & - & + \\
S. zooepidemicus & - & + & + & $+(-)$ \\
\hline
\end{tabular}

$\mathrm{V}$ : variable reaction, (-): few strains are negative

TABLE 3. demonstrate relation between seasonal incidence of strangles and age of animals according to PCR results.

\begin{tabular}{ccccc|ccc}
\hline & \multicolumn{3}{c|}{ Seasonal incidence } & \multicolumn{3}{c}{ Age } \\
\cline { 2 - 7 } $\begin{array}{c}\text { Epidemiological } \\
\text { parameter }\end{array}$ & Winter & Spring & Summer & Autumn & $\begin{array}{c}\text { Younger than } \\
\text { 6 months }\end{array}$ & $\begin{array}{c}\text { From 6 } \\
\text { monthsto 1 } \\
\text { year }\end{array}$ & $\begin{array}{c}\text { Above 1 } \\
\text { year }\end{array}$ \\
\hline $\begin{array}{c}\text { PCR results } \\
(\mathrm{n}=56)\end{array}$ & 32 & 12 & 9 & 0 & 12 & 41 & 3 \\
$\begin{array}{c}\text { Percentage (\%) } \\
\text { (5) }\end{array}$ & $57.14 \%$ & $21.43 \%$ & $16.07 \%$ & $0 \%$ & $21.42 \%$ & $73.21 \%$ & $5.36 \%$ \\
\hline
\end{tabular}


TABLE 4. Results of the antimicrobial sensitivity for the isolated Streptococcus spp. (56 isolates).

\begin{tabular}{lcccc}
\hline Antibiotic & Conc. & $\begin{array}{c}\text { No. of sensitive } \\
\text { isolates }\end{array}$ & $\begin{array}{c}\text { No. of resistant } \\
\text { isolates }\end{array}$ & Percent \\
\hline Penicillin G & $10 \mathrm{U}$ & 52 & 4 & 92.86 \\
Tetracycline (TE) & $30 \mu \mathrm{g}$ & 0 & 56 & 00.00 \\
Ciprofloxacine (CPFX) & $30 \mu \mathrm{g}$ & 3 & 53 & 5.66 \\
Ofloxacin (OFX) & $10 \mu \mathrm{g}$ & 50 & 6 & 89.29 \\
Erythromycin (E) & $10 \mu \mathrm{g}$ & 1 & 55 & 1.81 \\
Sulfa/trimethoprim & $25 \mu \mathrm{g}$ & 6 & 50 & 10.71 \\
(SXT) & $30 \mu \mathrm{g}$ & 3 & 53 & 5.66 \\
Cefotaxime (CTX) & $10 \mu \mathrm{g}$ & 0 & 56 & 00.00 \\
Ampicillin (AM) & $10 \mu \mathrm{g}$ & 0 & 56 & 00.00 \\
Gentamycin (CN) & $2 \mu \mathrm{g}$ & 0 & 56 & 00.00 \\
licomycin (L) & $30 \mu \mathrm{g}$ & 0 & 56 & 00.00 \\
Amikacin (KA) & & & & \\
\hline
\end{tabular}

\section{Discussion}

Strangles is one of the most commonly diagnosed contagious equine diseases worldwide, therefore, Strict hygiene procedures are essential to minimise the spread of infection especially in seasons which are characterized by high incidences like winter and spring. There is no one treatment plan that is suitable for every case of strangles. Treatment often revolves around supportive care, good stable management and hygiene, however, according to the study and the results of the antimicrobial sensitivity test, most of the isolates Streptococcus equi are susceptible for Penicilline G.

Related to the epidemiological results, Equines of any age may contract the disease, but elderly and younger equines are more susceptible, except foals less than four months who may be protected due to the colostrums derived passive immunity.

\section{References}

1. Harrington, D.J., Sutcliffe, I.C. and Chanter, N. (2002) The molecular basis of Streptococcus equi infection and disease. Microbes and Infection, 4 (4), 501-510.

2. Radositis, O.M., Gay, C.C., Hinchcliff, K.W. and Constable, P.D. (2007) Strangles (equine distemper), Part 2 special medicine, Veterinary Medicine a textbook of the diseases of cattle, sheep, goats, pigs and horses, $10^{\text {th }}$ ed., Saunders, pp. 769-775.
3. Mb, M., and Thiongane, Y. (2012). Note on epizootic infection for the chronic upper respiratory diseases caused by beta hemolytic Streptococcus equi observed on indigenous horses on Dakars region in Sngal. African Journal of Microbiology Research, 6 (6), 1109-1112.

4. Boyle, A.G. (2015), Diseases of Respiratory System, Chapter 31. Large Animal Internal Medicine,Smith, B.P. (Ed.) pp. 461-637.e37.

5. Ainsworth, D.M. and Cheetham J. (2010) "Disorders Of Respiratory System", chapter 9, $3^{\text {rd }}$ ed., Equine Internal Medicine, Reed,S.M., Bayly, W.M. and Sellon, D.C. (Ed.), pp.290-371

6. Higgins, A.J. and Snyder, J.R. (2006) "The Equine Manual" $2^{\text {nd }}$ ed., Elsevier Health Sciences, 75-81.

7. Khan, C.M. (2010) Respiratory System, Strangles, The Merck Veterinary Manual, Khan, C.M., $10^{\text {th }}$ ed., pp. 1339-1341.

8. Reed, S.M., Bayly, W.M. and Sellon, D.C. (2004) Streptococcusequi infection (strangles). Equine Internal Medicine. St. Louis, MO, Saunders, 308-312.

9. Sjöblom, A. (2014) Complications to strangles in horses presented at referral hospitals.

10. Manzoor, S., Siddique, M., Sajjad-Ur-Rahman and Ashraf, M. (2008) Occurrence of Lancefield Group C Streptococcus Species In Strangles Cases of foals In Punjab, Pakistan. Pakistan Vet. J., 28 (1), 17-20.

11. Timoney, J.F. (2004) The pathogenic equine streptococci.Veterinary research, 35 (4), 397409. 
12. Quinn, P. J., Markey, B. K., Leonard, F. C., FitzPatrick, E. S., Fanning, S., \&Hartigan, P. (2011) Veterinary microbiology and microbial disease. John Wiley \& Sons.

13. Ijaz, M. (2011)Epidemiology, diagnosis and chemotherapy of strangles in equine (Doctoral dissertation, University of Veterinary and Animal Sciences, Lahour).
14. Jannatabadi, A.A., Mohammadi, G.R., Rad, M. and Maleki, M. (2008) Molecular identification of Streptococcus equi subsp. equi and Streptococcus equi subsp. zooepidemicus in nasal swabs samples from horses suffering respiratory infections in Iran. Pakistan journal of Biological Sciences: PJBS, 11 (3), 468-471.

(Received 11/ 7/ 2017; accepted 6 / 8/ 2017)

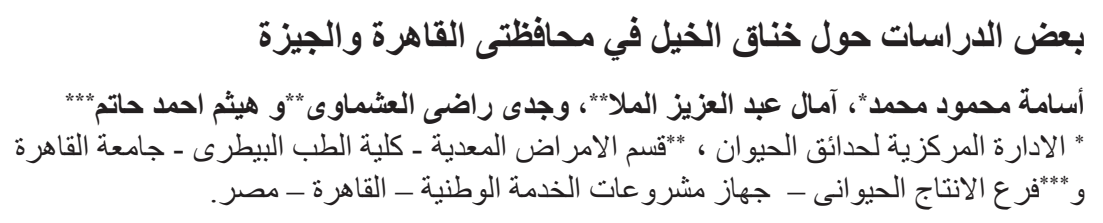

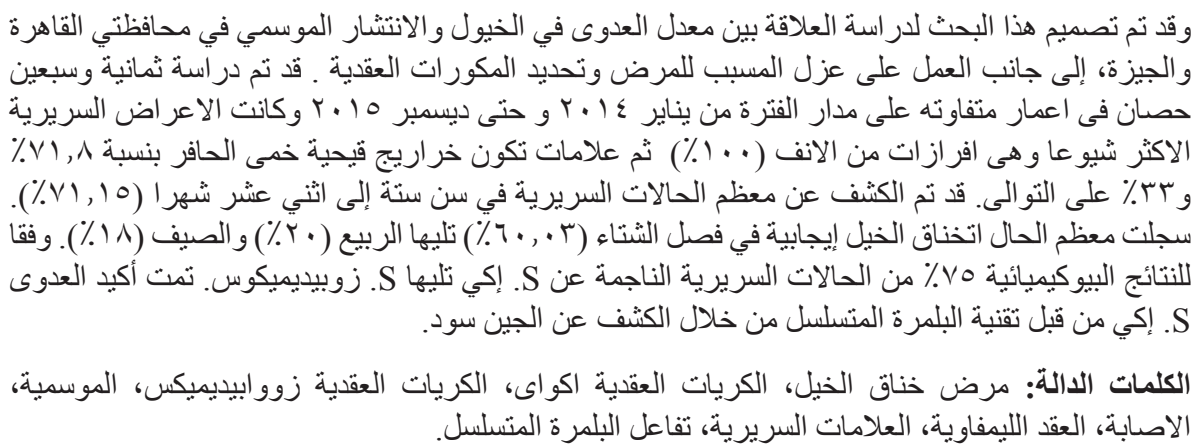

Egypt. J. Vet. Sci. Vol. 48, No. 2 (2017) 